\title{
POLÍTICA EXTERNA BRASILEIRA, MODELO DE DESENVOLVIMENTO E COALIZÕES POLÍTICAS (1930-2016)
}

\author{
Brazilian foreign policy, development model and political coalitions (1930- \\ 2016)
}

\author{
Tiago Nery \\ Doutor em Ciência Política pelo Instituto de Estudos \\ Sociais e Políticos da Universidade do Estado do \\ Rio de Janeiro (IESP-UERJ) e membro da \\ carreira de Especialista em Políticas Públicas e \\ Gestão Governamental do Estado do Rio de Janeiro \\ (EPPGG). \\ Está vinculado à Subsecretaria de Relações \\ Internacionais do Estado do Rio de Janeiro \\ E-mail: tiagonnery@gmail.com
}

Informações do artigo

Recebido em 06/04/2017 Aceito em 26/05/2017

\begin{abstract}
Resumo
O artigo analisa as relações entre a política externa brasileira, o modelo de desenvolvimento econômico e as coalizões políticas entre 1930 e 2016. A primeira seção destaca a importância da dimensão doméstica da política externa, que é influenciada por valores e ideias de diferentes atores, a exemplo dos partidos políticos. A segunda seção analisa duas ideias-força que historicamente caracterizaram a política externa brasileira: autonomia e desenvolvimento. Apesar da importância de ambas, durante o nacionaldesenvolvimentismo a busca do desenvolvimento tornou-se o principal vetor da política exterior do país. A terceira seção analisa o governo Fernando Henrique Cardoso, destacando as relações entre as reformas econômicas, a coalizão política e a política externa. Na última seção, são analisados os governos Luís Inácio Lula da Silva e Dilma Rousseff. Esses governos se apoiaram em coalizões heterogêneas, ensaiaram uma política neodesenvolvimentista e adotaram uma política externa mais autônoma. A mudança na conjuntura internacional contribuiu para interromper os governos liderados pelo Partido dos Trabalhadores. Na conclusão, destacam-se a influência do modelo de desenvolvimento e das coalizões políticas na orientação da política externa brasileira.

Palavras-chave: Política externa brasileira.

Desenvolvimento. Coalizões.
\end{abstract}

\section{Introdução}

Este artigo pretende analisar as relações entre a política externa brasileira, o modelo de desenvolvimento e as coalizões políticas entre 1930 e 2016, destacando-se o período nacional-desenvolvimentista, o governo Fernando Henrique Cardoso, o governo Luís Inácio Lula da Silva e o primeiro mandato de Dilma Rousseff, além de mencionar a ruptura institucional ocorrida no início do seu segundo mandato. O texto está dividido em quatro seções, além da introdução e da conclusão.

A primeira seção analisa a importância da dimensão doméstica da política externa, que está situada na fronteira da política doméstica com a política internacional. Por um lado, trata-se de uma política pública gerada no interior do Estado. Por outro, a política externa 
também está condicionada à ordem assimétrica em que está inserida. Assim, para além da dimensão sistêmica, a política externa também é influenciada por valores e ideias de diferentes atores, a exemplo dos partidos políticos. Para analisar essas inter-relações, são utilizadas abordagens como a análise de política externa e a teoria da política burocrática, responsáveis pelo esforço de integração entre os níveis doméstico e internacional da política exterior.

Na segunda seção, são analisadas as relações entre a política externa brasileira e as ideias de autonomia e desenvolvimento. O significado concreto desses dois eixos explicativos tem variado de acordo com o sistema internacional e as coalizões políticas domésticas. As conjunturas críticas enfrentadas pelo Brasil no século XX transformaram profundamente os vínculos entre a política exterior, o modelo de desenvolvimento e o conceito de autonomia.

A terceira seção trata das relações entre as políticas doméstica e externa do governo Fernando Henrique. O Partido da Social Democracia Brasileira (PSDB) esteve à frente de uma coalizão liberal-conservadora que procurou restaurar a credibilidade do país através da implementação de políticas econômicas neoliberais e da adesão a regimes internacionais. Desse modo, o governo Fernando Henrique buscou obter as credenciais tidas como necessárias para que o Brasil pudesse inserir-se em condições favoráveis no cenário global.

A quarta seção analisa a política neodesenvolvimentista e a política exterior dos governos Lula e Dilma. Os governos do Partido dos Trabalhadores (PT) lideraram uma coalizão heterogênea que envolveu setores da burguesia e segmentos organizados e desorganizados das classes trabalhadoras. Nesse período, a política externa reincorporou metas de desenvolvimento e priorizou as coalizões Sul-Sul e a integração sul-americana. Todavia, mudanças na conjuntura internacional e o acirramento dos conflitos distributivos provocaram uma crise política e institucional com reflexos na política externa.

Na conclusão, destaca-se a influência da dimensão doméstica, sobretudo do modelo de desenvolvimento e das coalizões políticas, na orientação da política externa brasileira.

\section{As relações entre a política externa e a dimensão doméstica}

As relações internacionais e a política doméstica possuem diversas imbricações. Apesar de não serem idênticas e possuírem características próprias, as duas esferas são sobrepostas. Nesse sentido, o interno e o externo devem ser vistos como duas extremidades 
de um eixo continuum e não dimensões radicalmente demarcadas. Devido ao fato de a ação recíproca entre o doméstico e o internacional ser constante e complexa, e de ambos se encontrarem inter-relacionados, faz-se necessária uma abordagem que articule os dois níveis de análise.

Diante do domínio do realismo em relações internacionais, surgiu, entre as décadas de 1950 e 1960, a subdisciplina análise de política externa. O novo campo desafiou algumas suposições do realismo, com destaque para sua concepção de Estado, visto como um ator unitário em busca de seus interesses de maneira clara e racional. A subdisciplina foi responsável por criticar a noção de Estado como ator coletivo unitário através de análises voltadas à política doméstica, às rivalidades burocráticas e ao papel dos indivíduos, além de ter incorporado diversos atores não-estatais. Os analistas de política externa passaram a pesquisar os diferentes níveis de análise - indivíduo, Estado e sistema internacional - por considerarem que explicações sobre fenômenos políticos não poderiam restringir-se a apenas um deles (ALDEN; ARAN, 2012; BEACH, 2012; HILL, 2003).

Ao desafiar os pilares centrais do realismo, a análise de política externa procurou mostrar não apenas que sua abordagem, incorporando fatores domésticos, poderia oferecer uma consideração mais persuasiva da formulação da política externa, e de suas irracionalidades, mas também que era preciso identificar as formas pelas quais os ambientes domésticos e os processos dos países eram afetados por fatores externos. Assim, a análise de política externa passou a investigar questões relacionadas ao impacto do sistema internacional na política externa, à importância dos fatores domésticos em sua formulação e implementação e de que maneira diferentes processos decisórios afetavam as tendências e as ações da política exterior (BEACH, 2012; HALLIDAY, 2007).

Além da análise de política externa, a teoria da política burocrática, elaborada por Graham Allison e Philip Zelikow (1999), também contribuiu para diferentes abordagens da política externa. A teoria da política burocrática apontou os limites do modelo do ator racional e representou um esforço de integração dos níveis doméstico e internacional na análise de política externa. Ao realçar a importância da dimensão doméstica, a abordagem desafiou o ceticismo do realismo e colocou questões centrais da política interna na agenda das relações internacionais. Ademais, tornou mais complexas as análises sobre o processo decisório. Em vez de restritas a um ator racional e unitário, as decisões sobre a formulação de 
política externa passaram a ser vistas como resultado da disputa entre diferentes organizações e atores políticos.

A literatura em relações internacionais contém inúmeros argumentos sobre a importância da dimensão doméstica. Ocorre que as principais abordagens enfatizam os aspectos formais ou procedimentais dos relacionamentos entre os mais variados grupos internos, omitindo a política. Sem dúvida, as abordagens sobre a força ou a fraqueza dos Estados e de suas estruturas institucionais são importantes politicamente, pois afetam a possibilidade de realização de certas ações. No entanto, a ênfase nos procedimentos ou nas capacidades estatais obscurece a maneira pela qual a política impacta os resultados dessas ações. Para evitar esse reducionismo, é preciso analisar as coalizões políticas, os valores e os interesses que elas mobilizam para atingir seus objetivos e fazer com que determinadas decisões sejam adotadas pelos governos (GOUREVITCH, 1978).

Peter Gourevitch (1993) chamou de conjuntura crítica a combinação simultânea de transformações sistêmicas e domésticas. As conjunturas críticas são momentos nos quais os padrões dominantes de desenvolvimento doméstico e inserção internacional se esgotam e abrem espaço para o surgimento de novas coalizões, com reflexos na política econômica e na política externa. Gourevitch observa que os tempos de prosperidade obscurecem a importância do poder e da política que lhe conferem sustentação. Em tempos de crise, contudo, ficam claras as escolhas feitas entre as propostas conflitivas que surgem da política.

Ao analisar as coalizões políticas e suas ideias, chega-se à influência dos partidos políticos no processo decisório de política externa. Um exame das relações entre partido e política exterior revela que as escolhas de determinadas políticas são influenciadas pela orientação ideológica partidária e não do governo. Os partidos políticos utilizam suas fundações e redes internacionais como meios de complementar e até mesmo criticar a linha política defendida pela agência burocrática responsável pelas relações exteriores. Nesse sentido, as secretarias de relações internacionais dos partidos praticam alguma forma de política internacional que pode influenciar a política externa do país.

No mundo pós-Guerra Fria, marcado pela liberalização econômica, parece superada a ideia realista de que a política externa começa onde termina a política doméstica. $\mathrm{Na}$ realidade, os contornos da política externa são afetados pelo jogo estratégico entre atores domésticos na luta pelo poder. Isso significa que o chamado "interesse nacional" depende 
das preferências e dos interesses da coalizão política vencedora e não apenas pode mudar como também é objeto de conflito interno (LIMA, 2000; PINHEIRO; MILANI, 2012).

Os processos de internacionalização da economia e democratização da sociedade são fatores que contribuem para a politização da política externa. Por um lado, a integração à economia internacional e a abertura econômica contribuem para a politização da política externa em função dos impactos distributivos internos da maior participação no comércio internacional, visto que em uma economia aberta, há ganhos e perdas diferenciados para os diferentes interesses setoriais. ${ }^{1}$ Por outro, a democratização política permite a intensificação do debate de ideias e das discussões entre atores sociais distintos quanto à melhor forma de contemplar suas demandas. Assim, a pluralidade de atores contribui também para a politização das agendas de política externa (LIMA, 2000; PINHEIRO; MILANI, 2012).

Durante longo período, a política externa tendeu a ser considerada desconectada das demais políticas públicas, pois carregava sobre si uma áurea de particularidade, especialização e confidencialidade que a tornava acessível apenas a alguns poucos "especialistas" capazes de operá-la. No entanto, a reflexão acadêmica brasileira e internacional tem enfatizado cada vez mais a dimensão de política pública da política externa. De acordo com Letícia Pinheiro e Carlos Milani (2012, p. 334),

Ao assumirmos a política externa como uma política pública, estamos, portanto, trazendo a política externa para o terreno da politics, ou seja, reconhecendo que sua formulação e implementação se inserem na dinâmica das escolhas de governos que, por sua vez, resultam de coalizões, barganhas, disputas, acordos entre porta-vozes de interesses diversos, que expressam, enfim, a própria dinâmica da política. Em decorrência, estamos retirando a política externa de uma condição inercial associada a supostos interesses nacionais autoevidentes e/ou permanentes e protegidos das injunções conjunturais de natureza político-partidária. Portanto, estamos privando a política externa das características geralmente atribuídas (ou preconcebidas) ao que se chama de política de Estado, que nos levava a imputar à política externa uma condição de extrema singularidade em relação às demais políticas públicas do governo.

De certo modo, as políticas de Estado são também políticas de governo. Com a política externa brasileira não é diferente. Como toda política pública, ela sofre mudanças em suas agendas e em seus atores por motivos sistêmicos e de acordo com as agendas dos

\footnotetext{
${ }^{1}$ Segundo Maria Regina Soares de Lima (2000, p. 289), "quando, ao contrário, os custos e benefícios não se concentram em setores específicos, ou os resultados da ação externa são neutros do ponto de vista do conflito distributivo interno, a política externa produz bens coletivos, aproximando-se do seu papel clássico, de defesa do interesse nacional ou do bem-estar da coletividade".
} 
governos. Nesse sentido, a hipótese do insulamento burocrático do Itamaraty não expressa mais a realidade empírica da política exterior do país em tempos de globalização e democratização do Estado, processos que contribuem para tornar as agendas decisórias mais complexas, levando à participação de outras instituições públicas e de diferentes setores da sociedade civil.

\section{Política externa, autonomia e modelo de desenvolvimento}

A trajetória da política externa brasileira indica uma estreita vinculação entre o modelo de desenvolvimento e a inserção do país no sistema internacional. Durante o nacional-desenvolvimentismo entre 1930 e 1980, a busca do desenvolvimento tornou-se o principal vetor da política exterior. Todavia, nos anos 1990, as mudanças no contexto internacional e o esgotamento do projeto desenvolvimentista provocaram mudanças na orientação da política externa brasileira. Com a hegemonia neoliberal e a vitória de uma coalizão liberal-conservadora, houve uma alteração na forma como o Brasil se inseria no mundo.

Historicamente, duas ideias-força ajudam a explicar, juntamente com a memória institucional de sua principal agência burocrática, o Itamaraty, os principais traços de continuidade da política externa brasileira. A primeira é a ideia de autonomia, que fez com que ao longo do século XX a política exterior fosse marcada pela busca de recursos de poder que garantissem maior autonomia do país no plano mundial, mesmo quando essa estratégia envolvia o alinhamento com determinada potência. O segundo eixo é a busca do desenvolvimento econômico, que significou o empenho em identificar os recursos externos que, em diferentes conjunturas internacionais, pudessem ser mobilizados para atender ao imperativo interno do desenvolvimento. Durante o período nacional-desenvolvimentista, essas duas linhas mestras se traduziram em identificar as modalidades possíveis de uma integração controlada na economia mundial, mobilizando recursos para aprofundar a industrialização e o desenvolvimento. Traduziu-se também em um esforço de construir o espaço da autonomia nacional, por meio de um relativo distanciamento em relação aos polos de poder do sistema internacional (LAFER, 2004; PINHEIRO, 2004).

A ideologia da autonomia e do desenvolvimento enfatizava tanto a economia capitalista mundial, que conteria mais restrições do que oportunidades, quanto o sistema 
político internacional, no qual a hegemonia dos Estados Unidos era vista como um obstáculo à conquista do desenvolvimento brasileiro e à sua capacidade de alcançar melhores posições na hierarquia do poder internacional. A partir da década de 1950, quando os fundamentos do projeto desenvolvimentista ganharam contornos mais nítidos, setores da elite e da sociedade passaram a defender que a política externa apoiasse o esforço de desenvolvimento (CERVO, 2003; LAFER, 2004).

No entanto, a tese de que a busca da autonomia constitui um traço perene da política externa brasileira deve ser criticada. Tal hipótese se apoia no falso pressuposto de que sempre houve consenso nacional sobre a inserção do Brasil no mundo. Por ser essencialmente político, o conceito de autonomia está relacionado com a ideologia predominante nas coalizões políticas domésticas. Entre 1930 e 1989, houve consenso apenas em relação aos aspectos econômico-comerciais do modelo de desenvolvimento, o que não ocorreu em relação à dimensão política e ao significado do conceito de autonomia. Assim, por exemplo, durante a Política Externa Independente (PEI), a diplomacia brasileira procurou garantir a soberania do país, e internamente, melhorar as condições de vida da classe trabalhadora, que então integrava a coalizão desenvolvimentista no poder. O mesmo não pode ser dito dos objetivos da política externa do regime militar, que apoiou um projeto de modernização excludente.

O principal fator que explica a continuidade, as mudanças e as rupturas da política externa brasileira é o modelo de desenvolvimento nacional e não o regime político. De fato, não há uma relação causal necessária entre regime político e política externa, pois uma mudança na natureza do primeiro não determina uma alteração no conteúdo da última. Portanto, a política externa pode ser alvo de uma revisão profunda sem que ocorra alteração do regime político. Durante o nacional-desenvolvimentismo, a política exterior converteu-se em instrumento de apoio ao projeto de industrialização, tanto nos governos democráticos quanto nos autoritários. No entanto, deve-se chamar a atenção para o fato de que a implantação de um mesmo modelo de desenvolvimento não implica a adoção de uma única linha de política externa (BERNAL-MEZA, 2003; CERVO, 2003; PINHEIRO, 2004).

O nacionalismo econômico teve suas origens no período 1930-1945, quando ocorreu uma primeira e limitada tomada de consciência da problemática da industrialização por parte de uma nova elite técnica, civil e militar, que então se instalava nas instituições estatais criadas após a Revolução de 1930. No entanto, o desenvolvimentismo, ou seja, a ideologia de 
superação do subdesenvolvimento nacional com base na acumulação de capital na indústria, somente se tornaria hegemônico na segunda metade dos anos 1950. O desenvolvimentismo era uma estratégia nacional de desenvolvimento acelerado, cuja liderança coube a uma coalizão de classes que envolvia os empresários industriais, a tecnoburocracia pública e privada e os trabalhadores urbanos (BIELSCHOWSKY, 2000; BRESSER-PEREIRA, 2009).

Entre 1947 e 1980, o crescimento médio da economia brasileira foi acima de $7 \%$ ao ano (CANO, 2014; CARDOSO, 2010). Após várias etapas do modelo substitutivo, o país dispunha de uma matriz interindustrial praticamente completa, especialmente em áreas estratégicas de insumos básicos e bens de capital, que Vargas tinha percebido como de fundamental importância para ordenar o crescimento econômico brasileiro. Durante o II Plano Nacional de Desenvolvimento, entre 1974 e 1979, o Brasil aplicou sua versão mais avançada do projeto nacional-desenvolvimentista, aprofundando o processo substitutivo de importações, com vistas a tornar-se autossuficiente em insumos básicos e, se possível, em energia. A transformação da estrutura produtiva brasileira pode ser verificada na Tabela 1.

Tabela 1 - Brasil: distribuição percentual do PIB por setor econômico

\begin{tabular}{ccc}
\hline Agropecuária & Serviços & Indústria de transformação \\
\hline 25,1 & 53,3 & 19,3 \\
18,3 & 51,5 & 26,3 \\
12,3 & 56,2 & 29,3 \\
10,9 & 52,7 & 33,7 \\
8,1 & 70,3 & 26,5 \\
5,6 & 66,7 & 17,2 \\
5,3 & 66,6 & 16,2 \\
5,7 & 69,3 & 13,1 \\
5,0 & 71,2 & 12,0 \\
\hline
\end{tabular}

Fonte: Instituto Brasileiro de Geografia e Estatística - IBGE (2016).

Apesar de não ser uma instituição criada pelo modelo de desenvolvimento baseado na industrialização por substituição de importações, o papel do Itamaraty foi central à consolidação doméstica do modelo e ao seu reconhecimento internacional. De acordo com Maria Regina Soares de Lima e Monica Hirst (2009, p. 48),

Uma ligação estreita e virtuosa foi estabelecida entre os objetivos da ISI e o objetivo de construção de uma política externa autônoma. Isto teve duas consequências. Primeiro, o Itamaraty obteve considerável legitimidade doméstica por seu papel como um dos principais instrumentos de 
desenvolvimento do país. Segundo, o Itamaraty adquiriu poderosa "memória institucional" na qual muitas das características e valores associados ao ISI retiveram influência e atratividade, mesmo após o declínio desse modelo de desenvolvimento.

Durante o nacional-desenvolvimentismo, as políticas comerciais estiveram subordinadas aos objetivos de política externa. Na época, a clivagem Norte-Sul desempenhava um papel decisivo tanto na explicação das dificuldades enfrentadas pelo Brasil para atingir suas metas econômicas, quanto na definição dos parâmetros que orientavam a formação de alianças e coalizões necessárias para alavancar os interesses do país na esfera internacional. No período da Guerra Fria, a política externa brasileira adotou posição discreta em assuntos relativos à paz e à segurança internacional, pois a participação do país nos fóruns multilaterais era influenciada principalmente pelo objetivo de promover o desenvolvimento econômico (LIMA; HIRST, 2009; MOTTA VEIGA, 2007). Havia, portanto, um consenso em torno do modelo de desenvolvimento, mas não em relação à dimensão política da política exterior. Essa é uma das razões que explicam porque o Brasil integrou o G77, com o qual compartilhava os desafios de superar a pobreza e o subdesenvolvimento, mas foi apenas um observador do Movimento Não Alinhado, que desafiava a bipolaridade entre os Estados Unidos e a União Soviética.

Ao analisar as conjunturas críticas que atingiram o Brasil, Lima e Hirst (2009) identificam duas delas ao longo do século XX: a primeira nos anos 1930, com a crise da economia agroexportadora e a subsequente adoção do modelo de industrialização por substituição de importações; e a segunda na década de 1990, com o esgotamento do modelo substitutivo e o advento de uma lógica de integração competitiva à economia global. Ambas provocaram rearticulações que envolveram as dimensões doméstica e internacional.

As crises são momentos de risco e também de oportunidade. Segundo Gourevitch (1993), as ideologias econômicas possuem considerável significado político, pois traçam o mapa dos objetivos e requerimentos políticos, das alianças e coalizões políticas. No caso brasileiro, a crise de 1929 permitiu o surgimento de uma coalizão que passou a defender a industrialização do país. Apesar da oposição sofrida pelas forças liberais e dos conflitos no interior da coalizão, o consenso em torno do desenvolvimento industrial perdurou por quase sessenta anos. Nos anos 1990, a crise do modelo de desenvolvimento e o avanço do neoliberalismo provocaram o fim da coalizão nacional que havia sustentado o projeto de 
industrialização, levando à adesão de segmentos expressivos das elites industriais às políticas neoliberais.

Com a crise do projeto de industrializante, a falta de consenso que havia em relação à ideia de autonomia se estendeu ao modelo de desenvolvimento. Os conflitos políticoideológicos atingiram a política externa, refletindo a ausência de um consenso nacional sobre um novo projeto de desenvolvimento. Com efeito, há diferenças entre o desejo de inserção global contido na política externa do governo Fernando Henrique e a proposta de inserção autonômica da política externa do governo Lula. Marco Aurélio Garcia (2014: 98) tem razão quando afirma: "é bom eliminar assim a ideia falsa de que a política externa não divide. Ela pode dividir, sim, e é bom que assim o seja, como ocorre nas democracias". Com isso, podese afirmar que a política externa e a inserção internacional de um país refletem a dinâmica do poder doméstico e os interesses da coalizão política hegemônica.

\section{Governo Fernando Henrique: reformas de mercado e diplomacia das credenciais}

O governo Fernando Henrique Cardoso (1995-2002) implementou políticas que alteraram profundamente o modelo econômico, a sociedade e a inserção internacional do Brasil. Por um lado, as reformas liberais, conquanto mais moderadas do que nos demais países latino-americanos, desmontaram sistematicamente 0 modelo nacionaldesenvolvimentista. Por outro, apesar da importante conquista da estabilidade monetária, as políticas ortodoxas geraram efeitos adversos na estrutura produtiva e no tecido social. Nesse contexto, a política externa brasileira tornou-se subsidiária à estabilidade macroeconômica, adquirindo a função de garantir a credibilidade por meio da modernização econômica e da maior participação do país nos regimes internacionais.

Nos anos 1990, os governos brasileiros adotaram uma agenda de desenvolvimento baseada no mercado, que responsabilizava o modelo de substituição de importações e o tamanho do Estado pelos problemas econômicos estruturais do país. A partir de 1995, Fernando Henrique acelerou o processo de abertura e privatização na tentativa de superar a Era Vargas. Por meio de emendas à constituição, redefiniram-se as relações entre o Estado e o setor privado. Muitas áreas anteriormente operadas pelo Estado foram abertas aos investidores privados. Foram privatizados os bancos estaduais, a Companhia Vale do Rio Doce e o sistema Telebrás, totalizando receitas superiores a US\$100 bilhões. Em tese, 0 
objetivo já não era apenas privatizar para liberar o Tesouro do ônus de sustentar algumas empresas deficitárias, mas ter uma estratégia de integração competitiva do país à economia internacional, atraindo capitais e tecnologia do exterior. Na prática, todavia, o investimento externo direto não se converteu em expansão da capacidade produtiva, mas na desnacionalização e na concentração das empresas, além da entrada de capital especulativo atraído pelas altas taxas de juros (CARDOSO, 2010; KERSTENETZKY, 2014; PEDERSEN, 2008).

O governo Fernando Henrique foi marcado pela ausência de uma política industrial ativa. A criação do Ministério do Desenvolvimento, Indústria e Comércio Exterior (MDIC), em 1998, veio acompanhada de medidas de concessão de empréstimos para as exportações. No entanto, o plano "Nova Política Industrial: Desenvolvimento e competitividade" não previa instrumentos de política industrial, mas apenas reiterava a importância da competitividade e da estabilidade macroeconômica (PEDERSEN, 2008). No âmbito do governo, havia uma predominância dos setores neoliberais ortodoxos, colocando em posição minoritária os chamados desenvolvimentistas, que defendiam uma política industrial ativa. Apesar do entusiasmo que o empresariado industrial demonstrou pela estabilização monetária, o apoio do setor ao governo começaria a minguar ainda no primeiro mandato (NOBRE, 2013).

A reestruturação produtiva intensificou a especialização das empresas domésticas, tornando as que sobreviveram mais competitivas. Todavia, a diminuição da diversificação favoreceu indústrias com baixo conteúdo tecnológico, concentradas em commodities industriais, a exemplo do aço, reforçando a chamada "especialização regressiva". Além disso, entre os efeitos deletérios da reestruturação produtiva estavam a desindustrialização e o aumento do desemprego. Os esforços internos em P\&D nas empresas privatizadas foram reduzidos, pois passaram a importar de suas matrizes e de seus fornecedores globais. As tecnologias de informática aplicadas à produção se disseminaram nas grandes firmas, em geral transnacionais, mas não entre as empresas pequenas e médias. Os reflexos dessas mudanças não tardaram a se refletir na pauta de exportações. Em 1990, a participação dos produtos industriais no total das exportações brasileiras era de 80,5\%; em 2000, já se encontrava em 32,1\% (CANO, 2014; DOMINGUES, 2009; KERSTENETZKY, 2014).

De acordo com os ideólogos do governo, o choque de concorrência desencadeado pela abertura levaria à reestruturação produtiva que, por sua vez, faria elevar os salários graças ao aumento da produtividade, contribuindo para o crescimento econômico e a 
redução das desigualdades distributivas. No entanto, a evolução desproporcional da produção vis-à-vis o emprego parecia indicar que equipamentos e processos poupadores de trabalho estavam sendo utilizados no curso da modernização industrial. Entre 1995 e 1999, extinguiu-se 1,8 milhão de empregos no setor formal, a maioria na indústria. O aumento da subcontratação e a dispersão geográfica das áreas industriais contribuíram para aprofundar a fragmentação da classe trabalhadora. Durante nove anos seguidos, entre 1995 e 2004, houve diminuição da participação salarial na renda nacional, que perdeu $9 \%$, enquanto as rendas de propriedade - aluguéis, juros, lucros, renda da terra - cresceram 12,3\% no mesmo período (DOMINGUES, 2009; KERSTENETZKY, 2014; PAULANI, 2008; POCHMANN, 2012).

No plano institucional, Fernando Henrique esteve à frente de uma ampla e sólida coalizão parlamentar, nucleada no PSDB, no Partido da Frente Liberal (PFL) e no Partido do Movimento Democrático Brasileiro (PMDB), a qual lhe proporcionou o governo mais estável, do ponto de vista político, dos dois períodos democráticos brasileiros (AMORIM NETO, 2011). A estabilização da economia teve como contrapartida a centralização dos instrumentos de política econômica no governo central, possibilitando a substituição do "velho pemedebismo" da década de 1980 por um "novo pemedebismo". Segundo Marcos Nobre (2013), em lugar dos dois extremos - o travamento pemedebista e o cesarismo de Collor surgiu um novo centro político e a partir dele dois polos, um liderado pelo PSDB e o outro pelo PT. Dessa forma, a polarização entre situação e oposição reorganizou o debate público, embora os canais de expressão da oposição fossem bastante limitados, em função tanto do superbloco parlamentar de apoio ao governo quanto do processo de desmobilização social que se seguiu à aplicação do receituário neoliberal. ${ }^{2}$

O governo Fernando Henrique liderou forças defensoras da ortodoxia neoliberal, ligadas ao capital financeiro, a frações da burguesia associadas ao capital internacional, às empresas de comunicação e à alta classe média dos setores público e privado. Os integrantes do governo que defendiam uma política industrial ativa eram minoritários e foram isolados. Ademais, a coalizão de centro-direita liderada pelo PSDB rejeitou qualquer aliança com movimentos e forças sociais organizadas. Com os empresários do setor industrial, as relações eram no mínimo truncadas. Nesse sentido, a coalizão de interesses rentistas teve sucesso na

\footnotetext{
2 Para Marcos Nobre (2013), o pemedebismo é um sistema de vetos capaz de travar mudanças profundas. A sua primeira figura foi o "Centrão" durante a Constituinte. Desde o impeachment de Collor, o pemedebismo assumiu a forma da necessidade de uma supermaioria parlamentar para garantir a governabilidade.
} 
aplicação das reformas liberalizantes e na da adaptação relativamente passiva do país à globalização econômica e financeira (BOITO; BERRINGER, 2014; DOMINGUES, 2013; NOBRE, 2013; SINGER, 2012).

$\mathrm{Na}$ política externa, Fernando Henrique exerceu ativamente a diplomacia presidencial, esvaziando o Itamaraty de algumas funções, uma vez que esse órgão ainda possuía alguns núcleos ligados ao projeto nacional-desenvolvimentista. O presidente transferiu certas atribuições econômicas do Ministério das Relações Exteriores (MRE) para o Ministério da Fazenda. Além disso, o novo mandatário procurou substituir uma agenda de política externa reativa - que havia prevalecido durante a vigência do modelo de substituição de importações - por uma agenda proativa, alinhada em alguns temas ao projeto neoliberal. Assim, em vez de uma autonomia isolacionista, buscou-se uma autonomia articulada com o meio internacional, baseada em uma estratégia de adesão unilateral a diferentes regimes internacionais. Na área ambiental, o Brasil caminhou rumo ao reconhecimento das questões ambientais, desempenhando um importante papel nas negociações da Rio-92. No campo dos direitos humanos, ratificou o Pacto Internacional sobre Direitos Civis e Políticos (1992), destacou-se na Conferência Mundial de Direitos Humanos em Viena (1993), anunciou que reconheceria a competência da Corte Interamericana de Direitos Humanos (1998) e decidiu assinar o estatuto do Tribunal Penal Internacional (1999). Na esfera de defesa, o país aderiu ao Tratado de Tlatelolco (1994), que previa a proibição de armas nucleares na América Latina e no Caribe; aprovou a legislação sobre o controle de exportação de materiais nucleares e ingressou no Regime de Controle de Tecnologia de Mísseis (1995); tornou-se membro do Grupo de Fornecedores Nucleares (1996); e ratificou o Tratado de Não Proliferação Nuclear (1998). Esse conjunto de medidas de contraproliferação, adotadas de maneira unilateral, alterou a auto-percepção do Brasil no sistema internacional (VIGEVANI; CEPALUNI, 2011; VISENTINI, 2013).

As prioridades da política externa passaram a subordinar-se à estabilização monetária e às reformas na economia. A política exterior passou a ter como objetivo primordial a restauração da credibilidade econômica e política do Brasil. Durante o primeiro mandato de Fernando Henrique (1995-1998), o sentido geral da política externa visava obter as credenciais entendidas como necessárias para que o país pudesse inserir-se em condições mais favoráveis no cenário internacional. Investiu-se pesadamente no soft power da credibilidade, que exigia a participação plena em todos os regimes internacionais. Nesse 
sentido, Alexandre Parola (2007) tem razão quando chama de "Diplomacia das Credenciais" a política externa do primeiro governo Fernando Henrique.

No segundo mandato de Fernando Henrique (1999-2002), houve uma combinação entre a deterioração do cenário econômico internacional, o aprofundamento da crise socioeconômica interna e a mudança do ambiente político mundial. O diagnóstico sobre as possibilidades de a ordem internacional acolher os interesses nacionais alterou-se sensivelmente. A visão otimista da globalização neoliberal foi substituída pela crítica à globalização assimétrica. Diante da falta de reciprocidade dos países europeus e dos norteamericanos, o governo brasileiro percebeu os limites de sua estratégia de inserção internacional, quando as credenciais já não bastavam (PAROLA, 2007; VIGEVANI; CEPALUNI, 2011).

Com a ascensão de George W. Bush em 2001, o unilateralismo da política externa estadunidense, sobretudo após os atentados de 11 de setembro, evidenciou ainda mais os limites da política externa brasileira. O governo Fernando Henrique vislumbrava encontrar uma parceria mais sólida com os países europeus, mas o compartilhamento de valores não foi suficiente para que houvesse uma reciprocidade da União Europeia (UE) em relação ao Brasil. A ausência de resultados concretos desacreditava a estratégia da busca por credibilidade, que nunca foi consensual no Estado, inclusive entre os membros da comunidade de política externa. No Itamaraty, abriu-se espaço para uma estratégia que fosse capaz de articular uma política neodesenvolvimentista com uma política externa ativa, com o objetivo de modificar a inserção do país no sistema internacional.

\section{Governos Lula e Dilma: ensaio desenvolvimentista e política externa autônoma}

Após duas décadas de hegemonia de governos neoliberais, a vitória de Luís Inácio Lula da Silva inaugurou um novo ciclo na região, com a ascensão de governos progressistas que introduziram políticas sociais distributivas, fortaleceram a capacidade de intervenção do Estado e formularam políticas externas mais autônomas. O declínio do projeto conservador cedeu lugar a processos de caráter endógeno, gerados nas lutas sociais de cada nação, levando ao surgimento de lideranças que conseguiram se firmar superando todos os preconceitos e quebrando as barreiras históricas impostas pelas elites desses países. Assim, 
o insucesso econômico e social das políticas neoliberais contribuiu decisivamente para a "virada à esquerda" dos governos da América do Sul durante a primeira década do século XXI.

Ao longo dos anos 1990, ocorreu uma "nacionalização" do PT, inserindo-o na tradição brasileira e latino-americana de projetos políticos pouco nítidos e de amplas coalizões, aglutinando forças com elementos díspares. Com isso, acentuou-se a necessidade, vivida há um século pela socialdemocracia europeia, de aproximar-se do centro para poder vencer eleições e governar, diluindo sua identidade classista e de esquerda (DOMINGUES, 2013; NOBRE, 2013; SINGER, 2012).

Segundo André Singer (2012), o lulismo caracteriza-se por uma orientação baseada na arbitragem pelo alto de interesses conflitantes. A partir de 2003 , houve a adoção de políticas para reduzir a pobreza e ativar o mercado interno, sem confronto com o capital. A fortuna da conjuntura internacional associada à virtù de apostar na redução da pobreza produziu o suporte material do lulismo. Isso provocou um realinhamento eleitoral e uma mudança na base social do PT, cristalizada a partir de 2006, com o afastamento da classe média e a adesão em bloco do subproletariado a Lula. O subproletariado é uma fração de classe que incorpora os empregados domésticos, os assalariados de pequenos produtores diretos e os trabalhadores destituídos das condições mínimas de participação na luta de classes. Assim, o lulismo aproveitou-se da onda de expansão mundial e optou por um caminho intermediário ao neoliberalismo da década anterior e ao reformismo forte que havia sido o programa do PT até sua chegada ao poder.

No plano das políticas sociais, o governo Lula aprofundou o modelo social inscrito na Constituição de 1988 e operou uma articulação entre a política macroeconômica e os programas sociais, combinando crescimento com distribuição de renda. No segundo mandato de Lula, a agenda social-desenvolvimentista ganhou contornos mais nítidos, quando a questão distributiva e as desigualdades - de renda, de poder, de reconhecimento social - passaram para o centro da arena política como ponto de disputa fundamental. A expansão dos programas de transferência de renda, com a criação do Ministério do Desenvolvimento Social (MDS) e do Programa Bolsa Família (PBF) em 2003, a extensão do financiamento popular via crédito consignado, e a valorização do salário mínimo a partir de 2005 contribuíram para o alívio da situação dos mais pobres e para o surgimento de um mercado interno de massa. No primeiro governo Dilma, nenhum investimento social sofreu cortes orçamentários. Os grandes programas sociais - o Minha Casa, Minha Vida e o Brasil 
sem Miséria - não só não foram afetados como também registraram expansão significativa (KAUCHAKJE, 2014; KERSTENETZKY, 2014; NOBRE, 2013; SINGER, 2012).

No âmbito das forças sociais, a aliança lulista apoiou-se em uma ampla coalizão que envolvia trabalhadores e setores empresariais. Essa frente neodesenvolvimentista tinha como programa a diminuição da taxa de juros, uma taxa de câmbio competitiva e a elevação dos investimentos em infraestrutura. Por um lado, o sindicalismo operário organizado fornecia um pilar organizativo e político ao governo, que contava ainda com o apoio eleitoral do subproletariado emergente. A esses setores se agregavam a pequena burguesia empobrecida e os trabalhadores rurais. Por outro, a aliança com o empresariado nacional foi progressivamente se firmando, sobretudo com a entrada definitiva do PMDB no governo. Entre os setores empresariais que integravam o pacto neodesenvolvimentista, destacavamse as grandes empreiteiras, as indústrias de processamento de commodities, as mineradoras, o setor de construção naval e segmentos do agronegócio. Nesse último caso, o boom de commodities teve grande influência na adesão, que continuou se ampliando no governo Dilma, momento em que se alinharam ao pacto até mesmo lideranças ruralistas tradicionais ligadas à Confederação da Agricultura e Pecuária do Brasil (BOITO; BERRINGER, 2014; DOMINGUES, 2013; NOBRE, 2013; SINGER, 2012).

Com a ascensão do PT, muitos analistas consideram que o governo brasileiro adotou um modelo neodesenvolvimentista, sobretudo a partir do segundo mandato de Lula (20072010) e durante o primeiro governo Dilma (2011-2014). O novo desenvolvimentismo é conceituado como uma estratégia de desenvolvimento para os países de renda média, no ambiente competitivo da globalização, e tem como elementos essenciais a intervenção moderada do Estado na economia, a manutenção de uma taxa de câmbio competitiva e uma ativa política social (BRESSER-PEREIRA, 2009; 2014).

A fim de consolidar a aliança com setores da grande burguesia interna, os governos Lula e Dilma optaram por um modelo de escolher "campeões nacionais", que recebem recursos e apoio do Banco Nacional de Desenvolvimento Econômico e Social (BNDES) para se estabelecer como plataformas de fornecimento, sobretudo de matérias-primas, para a economia mundial, controlando a abertura econômica de maneira a proteger a indústria instalada no território nacional. Trata-se de uma política neodesenvolvimentista que induz a criação de grandes conglomerados transnacionais baseados no país, empresas que devem ser capazes de integrar as cadeias produtivas ligadas à gangorra sino-americana e de exportar 
serviços e produtos a países da América Latina e da África. Nesse sentido, a política externa operou como um importante instrumento para fortalecer setores do grande capital nacional, que necessitam do apoio estatal para a abertura de novos mercados (BOITO; BERRINGER, 2014; NOBRE, 2013).

No entanto, alguns críticos questionam se os governos progressistas efetivamente adotaram um novo modelo de desenvolvimento. Para lan Carrillo (2014), as múltiplas contradições da trajetória do Brasil tornam problemática a afirmação de que o país adotou uma política neodensenvolvimentista nos últimos anos. Na realidade, os capitais públicos e privados continuaram sendo absorvidos pelos setores produtivos tradicionais, sem maior agregação de valor. Ao financiar setores primários em detrimento dos de alta tecnologia, o BNDES enfraqueceu o potencial do neodesenvolvimentismo e reforçou a dependência da trajetória vinculada ao modelo primário-exportador. Além disso, a inserção internacional brasileira baseou-se na demanda global por commodities, cujo ciclo de alta chegou ao fim, demonstrando a fragilidade do propalado novo modelo de desenvolvimento.

Desde 2013, a política econômica do governo começou a mostrar seus limites. No governo Lula, houve uma enorme apreciação cambial, que inviabilizou as exportações de manufaturados e agravou o processo de desindustrialização que vinha ocorrendo desde os anos 1990, como pôde ser observado na Tabela 1. Os efeitos desastrosos do câmbio valorizado viriam a ocorrer no governo Dilma, quando o aumento do mercado interno foi afinal capturado pelas importações. A presidente tentou compensar a moeda apreciada com uma agressiva política industrial, envolvendo a redução de impostos e a desoneração de encargos trabalhistas. Apesar do elevado custo para o Tesouro, a política não surtiu efeito, pois a moeda continuou valorizada (BRESSER-PEREIRA, 2014).

As taxas médias de crescimento da economia no período 2003-2010 foram praticamente o dobro das alcançadas pelo governo Fernando Henrique. No entanto, com a crise internacional e a queda nos preços das commodities, ficou difícil manter um modelo em que todos os setores da sociedade ganhavam. Na Tabela 2, é possível verificar as taxas médias de crescimento do PIB entre 1995 e 2014. A redução do crescimento no governo Dilma levou ao acirramento do conflito social em seu segundo mandato e à ruptura institucional. 
Tabela 2 - Brasil: taxas médias de crescimento do PIB nos Governos Fernando Henrique, Lula e Dilma (1995-2014)

\begin{tabular}{lcc}
\hline Governo & Período & Média (\%) \\
\hline Fernando Henrique & $\mathbf{1 9 9 5 - 2 0 0 2}$ & $\mathbf{3 , 2}$ \\
& $1995-1998$ & 3,4 \\
& $1999-2002$ & 3,1 \\
\multirow{3}{*}{ Lula } & $\mathbf{2 0 0 3 - 2 0 1 0}$ & $\mathbf{4 , 8}$ \\
& $2003-2006$ & 3,6 \\
\multirow{2}{*}{ Dilma } & $2007-2010$ & 6,0 \\
\hline
\end{tabular}

Fonte: FMI (2015).

Para entender a crise que atingiu o pacto lulista, faz-se necessária uma breve análise das duas coalizões contrapostas que se estruturam nos últimos anos, a "rentista" e a "produtivista". Enquanto a coalizão rentista abrangia o capital financeiro, o agronegócio e a classe média tradicional dos setores privado e público, a produtivista era formada por empresários industriais ou grande burguesia interna, frações organizadas da classe trabalhadora, classe média baixa e trabalhadores rurais empobrecidos. Acima de ambas, com o suporte do subproletariado, os governos petistas fizeram uma permanente arbitragem de acordo com a correlação de forças, ora dando ganho de causa a uma, ora à outra coalizão (BOITO; BERRINGER, 2014; SINGER, 2015).

O programa da coalizão rentista pretendia manter o Brasil alinhado às políticas neoliberais, bem como na órbita do grande capital internacional e da liderança geopolítica dos Estados Unidos. Por sua vez, o programa da coalizão produtivista visaria a acelerar o ritmo de crescimento por meio de uma intervenção do Estado que levasse à reindustrialização, o que possibilitaria intensificar a distribuição de renda. No entanto, a relação inicial favorável entre Estado e industriais acabou levando a uma campanha massiva, amplificada pelos meios de comunicação, contra a excessiva "estatização" da economia (SINGER, 2015).

No início de 2011, os produtivistas apresentaram o documento Brasil do diálogo, da produção e do emprego, assinado pela Federação das Indústrias do Estado de São Paulo (FIESP) e pelas principais centrais sindicais, propondo medidas para alavancar o setor produtivo. Apesar de Dilma ter adotado muitas propostas do documento, como a redução dos spreads bancários, as desonerações tributárias, a adoção do conteúdo nacional como diretriz da política industrial, entre outras, os industriais foram progressivamente se 
afastando do governo, alinhando-se lentamente ao bloco rentista de oposição. Com a mudança da conjuntura internacional, provocada sobretudo pelo fim do chamado efeitoChina3, o empresariado modificou suas demandas. Desde então, formou-se uma espécie de frente única burguesa em torno de questões como corte de gastos públicos, rebaixamento do valor do trabalho e diminuição de proteção aos trabalhadores (SINGER, 2015).

A coalizão entre industriais e trabalhadores liderada pelo PT foi atingida pela mudança na conjuntura internacional. O início do primeiro mandato de Dilma em 2011 coincidiu com a segunda fase da crise financeira internacional iniciada em 2008. A vaga contracionista reduziu o crescimento mundial, que passou de uma média de $4,1 \%$ ao ano, entre 2000 e 2008, para 2,9\%, de 2009 a 2014. Além disso, a China decidiu diminuir suas taxas de crescimento, que recuaram dos dois dígitos do período 2001- 2007, para 6,9\% em 2015. Essa mudança no contexto internacional afetou duramente o "ensaio desenvolvimentista" do governo Dilma, cuja principal característica era o ativismo estatal na busca da reindustrialização (SINGER, 2016). Assim, o modelo em que todos ganhavam chegava ao fim. A partir de 2013, o fosso entre industriais e trabalhadores se aprofundou, preparando as condições que levaram ao afastamento da presidente Dilma, à retomada da ofensiva neoliberal e ao fim do ensaio desenvolvimentista.

No âmbito doméstico, a explicação para o fracasso do "ensaio desenvolvimentista" está na inflexão da burguesia industrial, que a partir de 2012 começa a migrar da coalizão produtivista para a rentista. Algumas características estruturais da burguesia industrial brasileira provocaram tensões na coalizão produtivista. Na realidade, a separação clássica entre as esferas produtiva e financeira nunca existiu. Lênin (2012) já havia destacado a impossibilidade de separar, sob o capitalismo, os investimentos "produtivos" dos "especulativos". No caso brasileiro, a dupla condição de industriais e rentistas restringiu o grau de empenho da plataforma produtivista. Segundo Singer (2016), enquanto a atividade produtiva leva os empresários a pressionar por crédito e juros baixos, impulsionando-os para uma aliança com os trabalhadores, o vínculo desses industriais com os interesses financeiros provoca um movimento na direção contrária. Com a queda do preço das commodities e o acirramento do conflito distributivo, os pequenos avanços da economia política do trabalho,

\footnotetext{
3 Entre 2002 e 2006, o crescimento da China contribuiu para o boom das commodities, que tiveram valorização média de $89 \%$ nesse período (SINGER, 2012).
} 
como a política de valorização real do salário mínimo, precipitaram a ruptura da coalizão produtivista, tornando os argumentos do neoliberalismo mais sedutores aos industriais.

Outra razão para a fragilidade da coalizão neodesenvolvimentista reside no âmbito político-partidário. As forças políticas conservadoras, orientadas pela ortodoxia neoliberal, encontrariam canal privilegiado no PSDB. De modo diverso, a coligação produtivista ou neodesenvolvimentista não disporia de expressão partidária equivalente, visto que o PT permaneceu como partido próximo ao movimento sindical, sem vínculos orgânicos com o empresariado industrial, embora tenha se aproximado desse grupo desde a eleição de 2002. Por sua vez, o Partido do Movimento Democrático Brasileiro (PMDB) teria logrado uma aproximação estreita com o agronegócio, setor que, da mesma maneira que o partido, oscilaria entre as duas coalizões principais (BOITO; BERRINGER, 2014; SINGER, 2015).

O governo Lula devolveu ao Itamaraty a posição estratégica na formulação e na implementação da política exterior. A política externa retomou algumas diretrizes da PEI e do Pragmatismo Responsável, como reafirmar a autonomia frente às grandes potências e ampliar os laços com países em desenvolvimento. Retomou inclusive o vínculo interno/externo que caracterizou a PEI, ao incorporar os trabalhadores à coalizão política do governo e introduzir uma dimensão social na política exterior. Em relação aos países centrais, adotou-se uma política externa revisionista moderada que buscou contribuir para uma nova configuração do poder mundial, sem confrontar os Estados Unidos. Em relação aos países em desenvolvimento, a política externa brasileira promoveu a institucionalização de coalizões Sul-Sul. Assim, a ideia de autonomia que orientou a política externa dos governos Lula e Dilma procurou influenciar os regimes internacionais por meio de coalizões de geometria variável, como o Fórum IBAS e os BRICS, contrabalançando a agenda das nações desenvolvidas. 4

No âmbito regional, o governo Lula conferiu prioridade à América do Sul. Diferentemente do governo Fernando Henrique, que concebia a integração nos marcos do regionalismo aberto, como plataforma para o fortalecimento da inserção competitiva do Brasil na economia mundial, o governo Lula procurou fortalecer a região economicamente, socialmente e politicamente. A inserção soberana do Brasil devia passar pela unidade da

\footnotetext{
4 O IBAS surgiv em 2003 e é formado por Índia, Brasil e África do Sul, constituindo uma das principais coalizões Sul-Sul da atualidade. Os BRICS são uma coalizão formada por Brasil, Rússia, Índia, China e África do Sul. Nos últimos anos, o grupo agregou ao potencial econômico uma dimensão geopolítica.
} 
América do Sul, concebida como um importante ator geopolítico e estratégico na cambiante ordem internacional (LIMA; DUARTE; 2013). Diante da disjuntiva de se inserir isoladamente ou em conjunto com os demais vizinhos, os governos Lula e Dilma compreenderam o papel que uma América do Sul unida poderia desempenhar em um mundo multipolar em formação. Assim, a perspectiva de um futuro compartilhado incentivou a ideia de autonomia e a construção conjunta de uma agenda sul-americana.

A importância atribuída à América do Sul culminou na criação de uma instituição política, a Unasul. Trata-se de um fórum de articulação política, um instrumento que confere à região maior autonomia no sistema internacional. No entanto, a criação da Unasul não contou com a simpatia dos Estados Unidos, pois a nova organização constitui uma tentativa de materializar um polo sul-americano sempre temido e evitado pela política externa norteamericana. Por sua vez, o Mercosul foi considerado o núcleo principal da integração sulamericana, tendo sido objeto de uma espécie de relançamento pelo governo Lula, que incrementou sua dimensão comercial e aprofundou sua institucionalidade, conferindo-lhe maior conteúdo político e ampliando a participação social no interior do bloco.

Nos últimos anos, começou a ganhar peso a tese de que o Mercosul seria um fator limitante da capacidade de diversificação das parcerias do país. Para a Confederação Nacional da Indústria (CNI) e a FIESP, o bloco seria uma âncora que atrapalharia o Brasil nas negociações internacionais, dificultando acordos bilaterais com os Estados Unidos e a UE. Muitos empresários vêm discutindo a possibilidade de converter a atual união aduaneira imperfeita em uma área de livre comércio, em consonância com o que tem sido defendido pelo PSDB. Nesse sentido, observa-se que a inflexão na política externa brasileira tem acompanhado as mudanças na visão da burguesia industrial sobre a inserção internacional do país. Em 2003, setores da indústria brasileira haviam apoiado a orientação lulista de bloquear a Área de Livre Comércio das Américas (Alca) e investir no relacionamento Sul-Sul, aproximando o Mercosul da China. Em 2013, entretanto, diferentes associações empresariais constatavam que o Mercosul não seria suficiente para tirar o Brasil do isolamento decorrente do não alinhamento com o bloco norte-americano. A fim de romper com o isolamento, o país deveria aderir a acordos plurilaterais como a Trans-Pacific Partnership (TPP) ou Parceria Transpacífico, e a Transatlantic Trade and Investment Partnership (TTIP) ou Parceria 
Transatlântica (SINGER, 2016). 5 Todavia, a recente vitória de Donald Trump nas eleições presidenciais dos Estados Unidos deverá atrapalhar os planos da atual coalizão governista de realinhar a política externa brasileira aos interesses norte-americanos.

Para Luis Fernandes (2016), a ruptura institucional em curso na América Latina não é um fenômeno exclusivamente brasileiro. Daí a importância de situá-la no contexto da transição estrutural no sistema internacional. No âmbito sistêmico, os Estados Unidos estão reagindo à ameaça representada pelos chamados "Estados revisionistas", aqueles que procuram alterar aspectos cruciais dos processos que compõem a ordem mundial, a exemplo dos países integrantes dos BRICS. Na esfera regional, a contraofensiva conservadora visa desestabilizar os governos progressistas que ascenderam ao poder na última década, promovendo a destituição de presidentes democraticamente eleitos, como ocorreu em Honduras em 2009 e no Paraguai em 2012. No Brasil, a ruptura da ordem democrática levou ao poder uma nova coalizão conservadora, que reunificou as elites empresariais, alterou radicalmente a política doméstica e mudou a orientação da política externa. Na realidade, a ruptura institucional visa reverter e inviabilizar o projeto regional que começou a ser estruturado a partir da eleição do governo Lula em 2002, que incluía um movimento associado de reposicionamento estratégico do Brasil e da América do Sul no mundo.

Nos últimos anos, o Brasil adotou uma política externa que questionou a ordem liberal, aprofundou a cooperação Sul-Sul, fortaleceu a integração regional e projetou geopoliticamente a América do Sul. No entanto, os impasses da coalizão produtivista e a ascensão de uma nova coalizão de poder, liderada pela aliança PMDB-PSDB, levaram à reorientação da política externa brasileira e da inserção do país no sistema internacional, esvaziando as relações Sul-Sul e aproximando o Brasil dos acordos promovidos pelos países desenvolvidos.

\section{Conclusão}

Neste artigo, verificou-se que a compreensão do processo decisório de política externa requer um modelo analítico que inclua a dimensão doméstica. Apesar da importância

\footnotetext{
5 A TPP envolve os Estados Unidos e outros onze países de três continentes, e a TTIP reúne os Estados Unidos e a UE. Ambas representam contribuem para dispersar os esforços da Organização Mundial de Comércio (OMC) e constituem uma tentativa de empurrar a China para a margem das políticas de comércio (RODRIK, 2015).
} 
do nível sistêmico ou estrutural de análise, somente investigando as fontes internas da política externa é possível analisar o papel do modelo de desenvolvimento, das coalizões políticas e das disputas de poder na formulação e na orientação de determinada política exterior.

O artigo investigou também a vinculação entre o projeto nacional-desenvolvimentista e as duas ideias-força que caracterizam a política externa brasileira: autonomia e desenvolvimento. Entre 1930 e 1980, contribuir para o desenvolvimento significava industrializar o Brasil. Já o conceito de autonomia implicava aumentar as margens de manobra do país no sistema internacional. Como lembra Gelson Fonseca Jr. (2004, p. 361), "[...] as expressões do que é autonomia variam histórica e espacialmente, variam segundo interesses e posições de poder". Assim, o significado concreto dos dois eixos explicativos varia de acordo com o sistema internacional em dado momento e com as coalizões políticas domésticas. Aliás, com a crise do nacional-desenvolvimentismo, que havia sido marcado pelo consenso industrializante, elementos políticos e ideológicos tornaram-se ainda mais relevantes para a compreensão da política externa brasileira.

Durante os governos do PSDB e do PT, observou-se a importância das ideias das coalizões de poder para a política externa e a inserção do Brasil no sistema internacional. No governo Fernando Henrique, a coalizão rentista, de caráter liberal-conservadora, implementou políticas liberalizantes e de estabilização monetária no plano doméstico e adotou uma política externa que enfatizava as relações com os centros hegemônicos. Diante da falta de reciprocidade dos países desenvolvidos, a diplomacia das credenciais entrou em crise.

Os governos Lula e Dilma adotaram uma política econômica neodesenvolvimentista apoiada por uma política externa que reincorporou os objetivos de desenvolvimento. Ambos lideraram uma coalizão produtivista heterogênea envolvendo setores empresariais e segmentos sindicalizados e desorganizados das classes trabalhadoras. No segundo mandato, Lula iniciou um ensaio desenvolvimentista que seria intensificado por sua sucessora. No governo Dilma, a mudança na conjuntura internacional provocou o aumento dos conflitos distributivos entre capital e trabalho e a dissolução da coalizão produtivista. Desde 2011, a situação mundial tornou-se menos propícia a soluções favoráveis às classes populares. Assim, a política em que todos ganhavam, característica do lulismo, chegou ao fim, resultando na formação de uma abrangente unidade antidesenvolvimentista. 
A atual crise político-institucional do Brasil interrompeu o ensaio desenvolvimentista e levou ao poder uma nova coalizão conservadora, que reunificou as elites empresariais, alterou radicalmente a política doméstica e mudou a orientação da política externa, que deixou de enfatizar as relações Sul-Sul e a integração regional, voltando a priorizar os vínculos com os centros hegemônicos.

Em síntese, ao longo deste artigo, procurou-se analisar como as coalizões políticas influenciam e condicionam a política externa e a inserção internacional do Brasil. Com o fim do consenso desenvolvimentista, as ideias e os valores das coalizões adquiriram ainda mais importância. As diferenças na política externa dos últimos governos demonstram que a busca da autonomia e do desenvolvimento não constitui uma característica perene da diplomacia brasileira. Por fim, a crise atual também expõe a fragilidade da democracia brasileira e a baixa adesão das classes dominantes aos valores democráticos.

\section{Referências}

ALDEN, C.; ARAN, A. Foreign policy analysis: new approaches. New York: Routledge, 2012.

ALLISON, G.; ZELIKOW, P. Essence of decision: explaining the Cuban Missile Crisis. $2^{\text {nd }}$ ed. New York: Longman, 1999.

AMORIM NETO, O. De Dutra a Lula: a condução e os determinantes da política externa brasileira. Rio de Janeiro: Editora Campus Elsevier e Fundação Konrad Adenauer, 2011.

BEACH, D. Analyzing foreign policy. London: Palgrave Macmillan, 2012.

BERNAL-MEZA, R. Política exterior de Argentina, Chile y Brasil: perspectiva comparada. In: SARAIVA, J.F.S. (Ed.). Foreign policy and political regime, Brasília: IBRI, 2003.

BIELSCHOWSKY, R. Pensamento Econômico Brasileiro: o ciclo ideológico do desenvolvimentismo. 4. ed. Rio de Janeiro: Contraponto, 2000.

BOITO, A.; BERRINGER, T. Social classes, neodevelopmentalism, and Brazilian foreign policy under presidents Lula and Dilma. Latin American Perspectives, vol. 41, nº 5, pp. 94-109, 2014.

BRESSER-PEREIRA, L.C. A construção política do Brasil: sociedade, economia e estado desde a independência. São Paulo: Editora 34, 2014.

Globalização e competição: por que alguns países emergentes têm sucesso e outros não.

Rio de Janeiro: Elsevier, 2009.

CANO, W. (Des)Industrialização e (Sub)Desenvolvimento. Disponível em:

$<$ http://centrocelsofurtado.org.br/congress02014/arquivos/file/Artigo\%20Wilson\%2oCano.pdf>.

Acesso em: 10 nov. 2014. 
CARDOSO, F.H. Xadrez internacional e social-democracia. São Paulo: Paz e Terra, 2010.

CARRILLO, I. The new developmentalism and the challenges to long-term stability in Brazil. Latin American Perspectives, vol. 41, $\mathrm{n}^{\circ}$ 5, pp. 59-74, 2014.

CERVO, A. Political regimes and Brazil's foreign policy. In: In: SARAIVA, J.F.S. (Ed.). Foreign policy and political regime, Brasília: IBRI, 2003.

DOMINGUES, J. M. A América Latina e a modernidade contemporânea: uma interpretação sociológica. Belo Horizonte: Editora UFMG, 2009.

O Brasil entre o presente e o futuro: conjuntura interna e inserção internacional. Rio de Janeiro: Mauad X, 2013.

FERNANDES, L. Transição global e ruptura institucional: a geopolítica do neogolpismo no Brasil e na América Latina. Princípios, n. 143, pp. 30-40, 2016.

FMI (2015). Dados sobre as taxas médias de crescimento do PIB nos Governos Fernando Henrique, Lula e Dilma, 1995-2014. Disponível em: http://www.imf.org/.

FONSECA JR., G. A legitimidade e outras questões internacionais. 2. ed. São Paulo: Paz e Terra, 2004 .

GARCIA, M. A. Avanços, impasses e desafios da integração. In: MARINGONI G.; SCHUTTE, G. R.; BERRON, G. (Orgs.). 2003-2013: uma nova política externa. Tubarão: Ed. Copiart, 2014.

GOUREVITCH, P. Políticas estratégicas en tiempos difíciles: respuestas comparativas a las crisis económicas internacionales. México, DF: Fondo de Cultura Económica, 1993.

. The second image reversed: the international sources of domestic politics. International Organization, vol. 32, n 4, pp. 881-912, 1978.

HALLIDAY, F. Repensando as relações internacionais. 2. ed. Porto Alegre: Editora da UFRGS, 2007.

HILL, C. The changing politics of foreign policy. London: Palgrave MacMillan, 2003.

IBGE. Sistema de Contas Nacionais Referência 2000 (IBGE/SCN 2000 Anual). Produto Interno Bruto (PIB) - referências 2000 e 2010. 2016. Disponível em: www.ipeadata.gov.br.

KAUCHAKJE, S. International modeling and Brazilian public policies for poverty reduction. Latin American Policy, v. 5, n. 1, p. 157-168, 2014.

KERSTENETZKY, C. L. The Brazilian social developmental state: a progressive agenda in a (still) conservative political society. In: WILLIAMS, M. (Ed.). The end of the developmental state? New York: Routledge, 2014. p. 172-196.

LAFER, C. A identidade internacional do Brasil e a política externa brasileira: passado, presente e futuro. 2. ed. São Paulo: Perspectiva, 2004.

LÊNIN, V. I. Imperialismo, estágio superior do capitalismo: ensaio popular. São Paulo: Expressão Popular, 2012. 
LIMA, M. R. S. Instituições democráticas e política exterior. Contexto Internacional, v. 22, n. 2, p. 265-303, jul./dez. 2000.

LIMA, M. R. S.; DUARTE, R. Diplomacia presidencial e politização da política externa: uma comparação dos governos FHC e Lula. Observador On-Line, Rio de Janeiro, v. 8, n. 9, p. 1-24, 2013.

LIMA, M. R. S.; HIRST, M. Brasil como poder intermediário e poder regional. In: HURRELL, A.; et al. Os Brics e a ordem global. Rio de Janeiro: Ed. FGV, 2009. p. 43-73.

MOTTA VEIGA, P. Política comercial no Brasil: características, condicionantes domésticos e policymaking. In: JANK, M. S.; SILBER, S.D. (Orgs.). Políticas comerciais comparadas: desempenho e modelos organizacionais. São Paulo: Editora Singular, 2007. p. 71-162.

NOBRE, M. Imobilismo em movimento: da abertura democrática ao governo Dilma. São Paulo: Companhia das Letras, 2013. 204 p.

PAROLA, A. G. L. A ordem injusta. Brasília: Fundação Alexandre Gusmão, 2007. 508 p.

PAULANI, L. Brasil delivery: servidão financeira e estado de emergência econômico. São Paulo: Boitempo, 2008. $150 \mathrm{p}$.

PEDERSEN, J. D. Globalization, development and the state. London: Palgrave Macmillan, 2008. $215 \mathrm{p}$.

PINHEIRO, L. Política externa brasileira, 1889-2002. Rio de Janeiro: Jorge Zahar Ed., 2004. 81 p.

PINHEIRO, L.; MILANI, C. R. S. Conclusão. In: (Orgs.). Política externa brasileira: a política das práticas e as práticas da política. Rio de Janeiro: FGV Editora, 2012. p. 331-345.

POCHMANN, M. Nova classe média? O trabalho na base da pirâmide social brasileira. São Paulo: Boitempo, 2012.127 p.

RODRIK, D. As confusas defesas de acordos comerciais. Valor Econômico, São Paulo, 15 jun. 2015. Disponivel em: <http://www.valor.com.br/opiniao/4093502/confusas-defesas-de-acordoscomerciais>. Acesso em: 20 jun. 2015.

SINGER, A. Cutucando onças com vara curta: o ensaio desenvolvimentista no primeiro mandato de Dilma Rousseff (2011-2014). Novos Estudos, nº 102, p. 42-71, 2015.

A (falta de) base política para o ensaio desenvolvimentista. In: SINGER, A; LOUREIRO, I. (Orgs.). As contradições do lulismo: a que ponto chegamos? São Paulo: Boitempo, 2016.

Os sentidos do lulismo: reforma gradual e pacto conservador. São Paulo: Companhia das Letras, 2012. $276 \mathrm{p}$.

VIGEVANI, T.; CEPALUNI, G. A política externa brasileira: a busca da autonomia, de Sarney a Lula. São Paulo: Editora UNESP, 2011. 226 p.

VISENTINI, P. F. A projeção internacional do Brasil, 1930-2012: diplomacia, segurança e inserção na economia mundial. Rio de Janeiro: Elsevier, 2013. 224 p. 


\section{Abstract}

This article aims to analyze the relationship among Brazilian foreign policy, the economic development model and political coalitions between 1930 and 2014. The article is divided in four sections, besides an introduction and a conclusion. The first section analyzes the importance of the domestic dimension of foreign policy. In addition to the systemic dimension, foreign policy is also influenced by values and ideas of different actors, such as political parties. The second section analyzes two key ideas that have historically characterized Brazilian foreign policy: autonomy and development. Despite the importance of both, during the national developmentalism period the pursuit of development has become the main vector of the Brazilian foreign policy. The third section analyzes Fernando Henrique Cardoso's government (1995-2002), highlighting the relationship among economic reforms, political coalition and foreign policy. Finally, the last section analyzes the governments of Luís Inácio Lula da Silva (2003-2010) and Dilma Rousseff (2011-2014). Both governments have relied on heterogeneous coalitions, have rehearsed a neodevelopmentalist policy and adopted a more autonomous foreign policy. The change in the international and domestic situation put an end in the governments led by the Workers Party. Synthetically, the conclusion highlights the influence of the developmental model and political coalitions on the orientation of Brazilian foreign policy.

Keywords: Brazilian foreign policy. Development. Coalitions. 